\title{
SISTEM INFORMASI AKUNTANSI PENERIMAAN KAS ATAS TRANSAKSI PELELANGAN IKAN PADA TEMPAT PELELANGAN IKAN (TPI) KECAMATAN KARANGSONG KABUPATEN INDRAMAYU
}

\author{
Ayu Indriani ${ }^{1}$,Turini ${ }^{2}$,Chairun Nas $^{3}$ \\ Universitas Catur Insan Cendekia \\ Jl. Kesambi 202, Kota Cirebon, Jawa Barat Tlp : (0231) 220250 \\ e-mail : ayuindriyani27@gmail.com,turini@cic.ac.id,chairun.nas@cic.ac.id
}

\begin{abstract}
ABSTRAK
Tempat Pelelangan Ikan (TPI) Karangsong merupakan salah satu unit usaha yang dikelola oleh Koperasi Perikanan Laut (KPL) Mina Sumitra Indramayu. TPI Karangsong menjadi pusat tempat penjualan ikan segar di wilayah Kabupaten Indramayu melalui proses pelelangan yang dilakukan setiap hari. Pada pencatatan untuk penerimaan kas atas transaksi pelelangan ikan masih dilakukan secara manual. Cara tersebut menggunakan laporan yang ditulis tangan oleh karyawan sehingga membutuhkan waktu yang lama dalam pencatatannya. Sistem ini dirancang untuk membantu kinerja pada bagian-bagian yang terkait di TPI Karangsong dalam mengelola data pelelangan ikan agar dapat meningkatkan hasil lelang dan pendapatan nelayan. Metode yang digunakan dalam pengumpulan data pada proyek ini menggunakan metode kualitatif. Hasil penelitian diperoleh bahwa terdapat konsumsi waktu yang banyak pada proses pencatatan hasil lelang dimana kegiatan lelang ikan milik nelayan yang lain harus segera dilaksanakan karena akan mempengaruhi mutu ikan.
\end{abstract}

Kata kunci : Koperasi, Perikanan, Akuntansi, Lelang, Nelayan

\begin{abstract}
The Karangsong Fish Auction Place is one of the business units managed by the Marine Fisheries Cooperative Mina Sumitra Indramayu. TPI Karangsong becomes the center for selling fresh fish in the Indramayu Regency area through an auction process that is carried out every day. The recording for cash receipts for fish auction transactions is still done manually. This method uses handwritten reports by employees so that it takes a long time to record. This system is designed to assist the performance of relevant sections in TPI Karangsong in managing fish auction data in order to increase auction results and fishermen's income. The method used in data collection in this project uses qualitative methods. The results showed that there was a lot of time consumption in the process of recording the results of the auction where the auction of fish belonging to other fishermen must be carried out immediately because it will affect the quality of the fish.
\end{abstract}

Keywords: Cooperatives, Fisheries, Accounting, Auctions, Fishermen

\section{PENDAHULUAN}

Perkembangan teknologi yang sangat pesat memberikan kemudahan setiap orang dalam melakukan pekerjaan di dalam berbagai aspek kehidupan. Teknologi informasi yang baik tentunya disesuaikan dengan kebutuhan perusahaan agar dapat digunakan secara maksimal. Demikian pula dengan badan usaha koperasi, kehadiran teknologi sangat membantu dalam setiap kegiatannya. Data yang telah terkomputerisasi dapat diakses dengan mudah sewaktu-waktu guna mengetahui perkembangannya. Tempat Pelelangan Ikan (TPI) Karangsong merupakan salah satu unit usaha yang dikelola oleh Koperasi Perikanan Laut (KPL) Mina

Sistem Informasi Akuntansi Penerimaan Kas Atas Transaksi Pelelangan Ikan Pada Tempat Pelelangan Ikan (TPI) Kecamatan Karangsong Kabupaten Indramayu -

(Ayu Indriani,Turini,Chairun Nas) 
Sumitra Indramayu. TPI Karangsong memegang peranan penting dalam pengelolaan perikanan yang baik agar bermanfaat secara optimal. Namun hasil tangkapan yang didaratkan di TPI Karangsong terkadang tidak dalam penanganan yang cepat pada hal pencatatan keuangan, sehingga dapat menghambat proses lelang selanjutnya dan berpengaruh pada mutu ikan yang akan berpotensi menurun.

Dari permasalahan tersebut diketahui bahwa pencatatan untuk penerimaan kas atas transaksi pelelangan ikan masih dilakukan secara manual. Cara tersebut menggunakan laporan yang ditulis tangan oleh karyawan sehingga membutuhkan waktu yang lama dalam pencatatannya. Selain itu, laporan yang masih manual bisa menyebabkan kehilangan atau kerusakan data seperti sobek atau basah terkena cairan. Sehubungan dengan latar belakang tersebut, maka penulis membuat sistem informasi akuntansi penerimaan kas atas transaksi pelelangan ikan yang akan membantu kinerja TPI Karangsong

\subsection{Identifikasi Masalah}

Berdasarkan latar belakang tersebut, maka penulis dapat merumuskan masalah sebagai berikut:

1. Bagaimana membuat proses pencatatan penerimaan kas atas transaksi pelelangan ikan pada Tempat Pelelangan Ikan (TPI) Karangsong Indramayu menjadi lebih efektif?

2. Bagaimana menerapkan pengendalian internal terhadap sistem pencatatan penerimaan kas atas transaksi pelelangan ikan pada Tempat Pelelangan Ikan (TPI) Karangsong Indramayu?

3. Bagaimana membuat sistem aplikasi berbasis web untuk pencatatan penerimaan kas atas transaksi pelelangan ikan pada Tempat Pelelangan Ikan (TPI) Karangsong Indramayu

\subsection{Batasan Masalah} berikut:

Dalam pembuatan tugas akhir ini, penulis membatasi permasalahan dengan prosedur-prosedur sebagai

1. Bagian terkait yang dapat mengakses sistem adalah sebagai berikut:

a. Bagian Kasir: melakukan input input data pembeli dan data pelelangan ikan. Kemudian bagian kasir membuat laporan pelelangan ikan dan nota lelang pembeli.

b. Bagian Administrasi: melakukan melakukan input data nelayan, data pendapatan nelayan, dan data penerimaan retribusi. Kemudian bagian administrasi membuat laporan data nelayan, nota lelang nelayan, jurnal penerimaan dan laporan penerimaan kas atas transaksi pelelangan ikan (retribusi).

c. Bagian Manajer: melakukan pengecekan terhadap laporan penerimaan kas atas transaksi pelelangan ikan (retribusi) dan laporan pelelangan ikan.

2. Pada sistem ini, kedudukan Tempat Pelelangan Ikan (TPI) adalah sebagai distributor antara nelayan dan pembeli ikan. Sehingga penerimaan kas bersumber dari jasa pelelangan ikan.

3. Pada tugas akhir sistem ini penerimaan kas dibatasi hanya dari biaya lelang ikan yang dibebankan kepada nelayan dan tidak termasuk biaya-biaya lain seperti biaya sewa basket/trays, dana muara, dan biaya nadran.

4. Pada sistem ini tidak membahas biaya yang dibebankan kepada pembeli ikan.

5. Prosedur akuntansi yang akan dibahas adalah prosedur pencatatan penerimaan kas atas transaksi pelelangan ikan.

6. Metode akuntansi yang digunakan pada sistem ini adalah metode cash basis.

7. Program aplikasi yang dibuat menggunakan bahasa pemrograman PHP (Hypertext Prepocessor) sedangkan untuk penyimpanan data menggunakan perangkat lunak MySQL.

\subsection{Tujuan Penelitian}

Berdasarkan rumusan masalah yang telah dijelaskan, penulis membuat tujuan sebagai berikut:

1. Membuat proses pencatatan penerimaan kas atas transaksi pelelangan ikan pada Tempat Pelelangan Ikan (TPI) Karangsong Indramayu menjadi lebih efektif.

2. Menerapkan pengendalian internal terhadap sistem pencatatan penerimaan kas atas transaksi pelelangan ikan pada Tempat Pelelangan Ikan (TPI) Karangsong Indramayu.

3. Membuat sistem aplikasi berbasis web untuk pencatatan penerimaan kas atas transaksi pelelangan ikan pada Tempat Pelelangan Ikan (TPI) Karangsong Indramayu.

\section{KAJIAN PUSTAKA}

\subsection{Pengertian Sistem}

Pengertian sistem menurut Mulyadi (2016:5) sistem adalah suatu jaringan prosedur yang dibuat menurut pola yang terpadu untuk melaksanakan kegiatan pokok perusahaan. Adapun karakteristik sistem adalah sebagai berikut: 
a. Sistem terdiri dari unsur-unsur

b. Unsur-unsur tersebut merupakan bagian terpadu dari sistem yang bersangkutan

c. Unsur-unsur sistem tersebut bekerjasama untuk mencapai tujuan sistem

Wongso (2016) menyatakan bahwa sistem adalah kumpulan atau rangkaian komponen-komponen yang saling berhubungan, bekerja sama dan saling berinteraksi untuk mencapai suatu tujuan dengan melalui tiga tahapan input (masuk), proses dan output (keluar). Sedangkan pengertian sistem menurut Romney dan Steinbart (2015:3) dalam bukunya yang berjudul Accounting Information System, mengatakan bahwa Sistem adalah rangkaian dari dua atau lebih komponen-komponen yang saling berhubungan, yang berinteraksi untuk mencapai suatu tujuan. Sebagian besar sistem terdiri dari subsistem yang lebih kecil yang mendukung sistem yang lebih besar.

\subsection{Pengertian Akuntansi}

Martani, dkk (2016:4) menyatakan bahwa akuntansi adalah bahasa bisnis (business langunge), akuntansi menghasilkan informasi yang menjelaskan kinerja keuangan entitas dalam suatu periode tertentu dan kondisi keuangan entitas pada tanggal tertentu. Informasi akuntansi tersebut digunakan oleh para pemakai agar dapat membantu dalam membuat prediksi kinerja di masa mendatang.

Informasi yang dihasilkan akuntansi diperlukan untuk:

1. Membuat perencanaan yang efektif, pengawasan dan pengambilan keputusan oleh manajemen,

2. Pertanggungjawaban organisasi kepada para investor, kreditur, badan pemerintah dan sebagainya.

Kartikahadi, dkk (2016:3) menyatakan bahwa akuntansi merupakan sebuah sistem informasi keuangan, yang memiliki tujuan untuk menghasilkan dan kemudian melaporkan informasi yang relevan untuk berbagai pihak yang berkepentingan. Berdasarkan pengertian diatas, dapat disimpulkan bahwa akuntansi adalah proses pencatatan, penggolongan, peringkasan, pelaporan dan penganalisisan data keuangan suatu organisasi yang dilaksanakan baik dalam perusahaan yang bertujuan mencari laba maupun organisasi yang tidak mencari laba.

\subsection{Pengertian Pelelangan Ikan}

Pelelangan adalah kegiatan pemasaran yang mempertemukan penjual dan pembeli. Dalam hal ini nelayan sebagai penjual hasil tangkapan, diwakili oleh petugas lelang. Pelelangan ikan merupakan salah satu mata rantai dari kegiatan usaha penangkapan. Nilai jual yang diperoleh nelayan akan lebih besar melalui proses lelang dibandingkan bila nelayan berhadapan langsung satu persatu dengan pembeli.

\subsection{Pengertian Pengendalian Internal}

Esteria, dkk (2016) menyatakan bahwa pengendalian internal adalah meliputi struktur organisasi dan segala cara serta tindakan dalam suatu perusahaan yang saling terkoordinasi dengan tujuan mengamankan harta kekayaan perusahaan, menguji ketelitian dan kebenaran data akuntansi, meningkatkan efisiensi operasi serta mendorong ketaatan terhadap kebijakan - kebijakan yang telah digariskan oleh pimpinan perusahaan.

Menurut Mulyadi (2016) sistem pengendalian internal meliputi struktur organisasi, metode dan ukuran - ukuran yang dikoordinasikan untuk menjaga aset organisasi, mengecek ketelitian dan keandalan akuntansi, mendorong efisiensi dan mendorong dipatuhinya kebijakan manajemen.

Menurut definisi disini, tujuan sistem pengendalian internal adalah sebagai berikut:

1. Menjaga aset organisasi dan mendorong efisiensi.

2. Mengecek ketelitian dan keandalan data akuntansi.

3. Mendorong dipatuhinya kebijakan manajemen.

\section{ANALISA SISTEM}

\subsection{Analisis Sistem Berjalan}

Analisa sistem merupakan penguraian dari informasi yang utuh ke dalam bagian-bagian kompenennya. Hal ini bertujuan untuk mendefinisikan, mengevaluasi permasalahan-permasalahan, kesempatan-kesempatan, hambatan-hambatan yang terjadi dan kebutuhan-kebutuhan yang diharapkan sehingga dapat diusulkan suatu upaya perbaikan-perbaikan. Analisa ini mencakup cara kerja sistem, perancangan sistem, perancangan tabel-tabel dan perancangan tampilan antar muka.

Sistem Informasi Akuntansi Penerimaan Kas Atas Transaksi Pelelangan Ikan Pada Tempat Pelelangan Ikan (TPI) Kecamatan Karangsong Kabupaten Indramayu - 


\subsection{Dokumen dan Catatan Akuntansi yang Digunakan}

Dokumen dan catatan akuntansi yang digunakan dalam sistem ini adalah sebagai berikut:

1. Karcis Lelang

Karcis lelang ini dibuat oleh juru karcis setelah satu transaksi pelelangan diselesaikan. Karcis lelang terdiri dari 3 (tiga) rangkap, rangkap pertama diberikan kepada bakul/pembeli, rangkap kedua diberikan kebagian adminstrasi dan rangkap ketiga diarsipkan. Dokumen ini berisi nomor karcis, nama nelayan, nama bakul/pembeli, jenis ikan, berat ikan, harga satuan (dalam Kg), jumlah harga, tanggal transaksi serta tanda tangan manajer TPI.

2. Nota Lelang Ikan

Rekenan Juragan ini ditulis oleh bagian administrasi, setelah itu diserahkan ke bagian kasir. Setelah data di input oleh kasir, rekenan juragan berikan ke nelayan sebagai tanda terima uang. Dokumen ini berisi nomor, nama nelayan, potongan biaya-biaya, dan potongan lainnya. Besaran biaya lelang sebesar 3\% ditentukan oleh Koperasi Perikanan Laut (KPL) Mina Sumitra sebagai instansi yang menaungi Tempat Pelelangan Ikan (TPI) Karangsong Indramayu.

\subsubsection{Laporan-Laporan Akuntansi yang Digunakan}

Laporan-laporan akuntansi yang digunakan dalam sistem ini adalah sebagai berikut:

Rekapitulasi Potongan TPI Rekapitulasi potongan TPI merupakan laporan yang dibuat bagian administrasi untuk merekap semua transaksi atas pelelangan ikan di TPI Karangsong termasuk semua potongan yang dibebankan kepada anggota koperasi atau nelayan. Potongan tersebut diantaranya biaya sewa basket/keranjang, dana muara, ongkos lelang nelayan, ongkos lelang bakul, dan simpanan.

\subsubsection{Bagian-bagian yang Terkait}

Berikut merupakan bagian yang terkait sistem informasi akuntansi penerimaan kas atas transaksi pelelangan ikan pada Tempat Pelelangan Ikan (TPI) Karangsong Indramayu:

1. Bagian Kasir

Bagian Kasir bertanggungjawab untuk melakukan input data pembeli dan data pelelangan ikan. Kemudian bagian kasir membuat laporan pelelangan ikan dan nota lelang pembeli.

2. Bagian Administrasi

Bagian administrasi bertanggungjawab untuk melakukan input data nelayan, data pendapatan nelayan, dan data penerimaan retribusi. Kemudian bagian administrasi membuat laporan data nelayan, nota lelang nelayan, jurnal penerimaan dan laporan penerimaan kas atas transaksi pelelangan ikan (retribusi).

3. Bagian Manajer

Bagian manajer bertanggungjawab untuk melakukan pengecekan terhadap laporan penerimaan kas atas transaksi pelelangan ikan (retribusi) dan laporan pelelangan ikan.

\subsection{Diagram Konteks (Context Diagram)}

Diagram konteks dalam perancangan sistem ini mencakup aliran input, proses, dan output. Diagram ini hanya memuat satu proses yang menunjukan sistem secara keseluruhan. Berikut rancangannya:

a. Diagram konteks (Context Diagram)

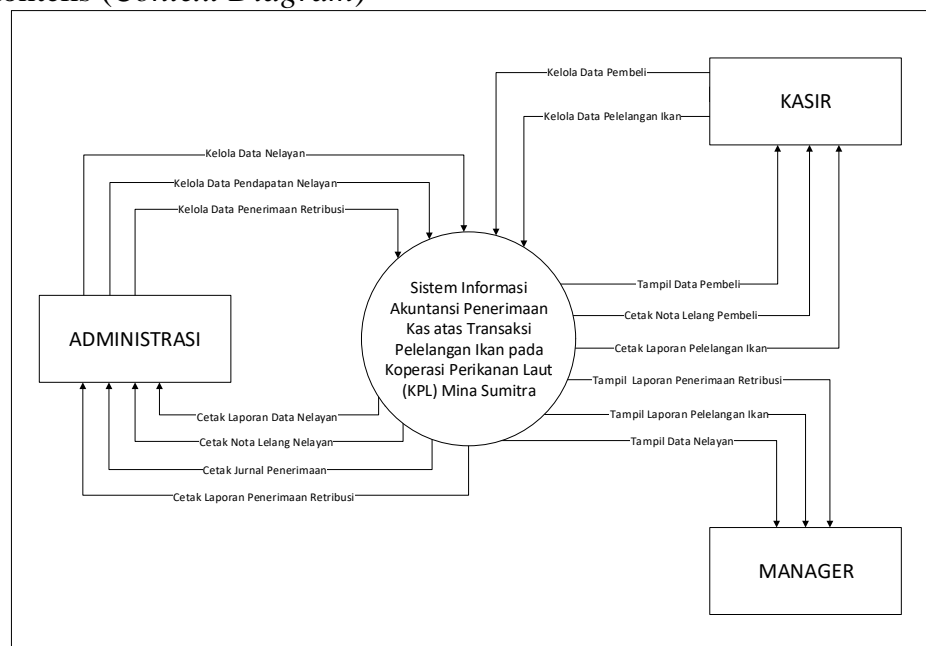

Gambar 1. Diagram Konteks Sistem Usulan 
b. Prosedur Naratif

1. Bagian administrasi melakukan kelola data nelayan, data pendapatan nelayan, serta data penerimaan retribusi. Kemudian bagian administrasi menghasilkan output laporan data nelayan, nota lelang nelayan, jurnal penerimaan dan laporan penerimaan retribusi.

2. Bagian kasir melakukan kelola data pembeli dan data pelelangan ikan. Kemudian bagian kasir menghasilkan output data pembeli, nota lelang pembeli, dan laporan pelelangan ikan.

3. Bagian manajer menampilkan laporan penerimaan retribusi, data nelayan, dan laporan pelelangan ikan.

\subsection{Diagram Alir Data (Data Flow Diagram/DFD) Level-0}

DFD level-0 merupakan tahap yang menggambarkan bagaimana arus data tersebut terpecah dari sub-proses utama dari diagram konteks menjadi bagian-bagian yang lebih sempit. Berikut adalah rancangannya:

a. Prosedur Naratif

1. Proses 1.0 kelola data nelayan, bagian admininstrasi melakukan input data nelayan kemudian data tersebut dikelola dan disimpan pada tabel nelayan yang menghasilkan output berupa laporan data nelayan.

2. Proses 2.0 kelola data pembeli, bagian kasir melakukan input data pembeli kemudian data tersebut dikelola dan disimpan pada tabel pembeli yang menghasilkan output berupa tampil data pembeli.

3. Proses 3.0 kelola data pelelangan ikan, bagian kasir dapat menampilkan data nelayan dari tabel nelayan dan data pembeli dari tabel pembeli. Bagian kasir melakukan input data pelelangan ikan kemudian data tersebut dikelola dan disimpan pada tabel pelelangan yang menghasilkan output berupa laporan pelelangan ikan dan nota lelang pembeli.

4. Proses 4.0 kelola data pendapatan nelayan, bagian admininstrasi dapat menampilkan data pelelangan ikan dari tabel pelelangan. Bagian administrasi melakukan input data pendapatan nelayan kemudian data tersebut dikelola dan disimpan pada tabel pendapatan yang menghasilkan output berupa nota lelang nelayan.

5. Proses 5.0 kelola data penerimaan retribusi, bagian admininstrasi dapat menampilkan data pendapatan nelayan dari tabel pendapatan. Kemudian dari data tersebut, bagain administrasi dapat menghasilkan output berupa jurnal penerimaan dan laporan penerimaan retribusi.

6. Proses 6.0 data nelayan, bagian manajer dapat menampilkan data nelayan dari tabel nelayan.

7. Proses 7.0 laporan pelelangan ikan, bagian manajer dapat menampilkan data pelelangan ikan dari tabel pelelangan.

8. Proses 8.0 laporan penerimaan retribusi, bagian manajer dapat menampilkan laporan penerimaan retribusi dari tabel penerimaan.

\subsection{Perancangan Basis Data}

Salah satu tahapan pada saat akan membuat aplikasi yakni merancang database atau basis data. Database digunakan sebagai media penampung data-data yang diinputkan pada program aplikasi. Rancangan database akan sistem ini menggunakan MySQL. Berikut merupakan gambaran rancangan database sistem informasi akuntansi penerimaan kas atas transaksi pelelangan ikan pada Tempat Pelelangan Ikan (TPI) Karangsong Indramayu.

\subsubsection{Rancangan Data Tabel}

Rancangan ini digunakan untuk menentukan field dan tipe data apa yang sesuai sebagai penunjang fungsi penyimpanan agar berjalan dengan baik.

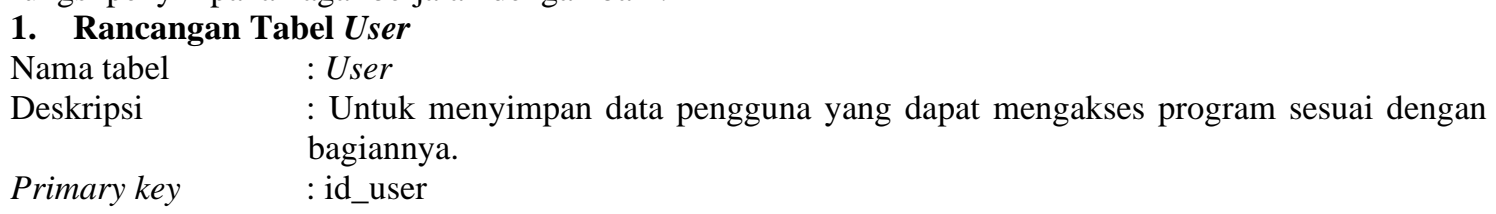

Sistem Informasi Akuntansi Penerimaan Kas Atas Transaksi Pelelangan Ikan Pada Tempat Pelelangan Ikan (TPI) Kecamatan Karangsong Kabupaten Indramayu - 
Tabel 1. Rancangan Tabel User

\begin{tabular}{|c|l|l|l|}
\hline No. & \multicolumn{1}{|c|}{ Nama } & \multicolumn{1}{c|}{ Tipe Data } & \multicolumn{1}{c|}{ Keterangan } \\
\hline 1 & id_user & Int(11) & $\begin{array}{l}\text { Nomor Id } \\
\text { pengguna }\end{array}$ \\
\hline 2 & nama_user & Varchar(50) & Nama pengguna \\
\hline 3 & username & Varchar(50) & Username \\
\hline 4 & password & Varchar(10) & Password \\
\hline 5 & bagian & Enum & Bagian pengguna \\
\hline
\end{tabular}

\section{Rancangan Tabel Nelayan}

Nama tabel

Deskripsi

Primary key
: Nelayan

: Untuk menyimpan data nelayan yang melakukan lelang di Tempat Pelelangan Ikan (TPI) Karangsong.

: id_nelayan

Tabel 2. Rancangan Tabel Nelayan

\begin{tabular}{|c|l|l|l|}
\hline No. & \multicolumn{1}{|c|}{ Nama } & \multicolumn{1}{c|}{ Tipe Data } & \multicolumn{1}{c|}{ Keterangan } \\
\hline 1 & id_nelayan & Int(11) & Nomor Id nelayan \\
\hline 2 & nama_nel & Varchar(50) & Nama pengguna \\
\hline 3 & nik & Char(30) & Nomor identitas nelayan \\
\hline 4 & nama_kapal & Varchar(50) & Nama kapal milik nelayan \\
\hline 5 & nahkoda & Varchar(50) & Nama nahkoda kapal \\
\hline
\end{tabular}

\section{Rancangan Tabel Pembeli}

Nama tabel

Deskripsi

Primary key

: Pembeli

: Untuk menyimpan data pembeli yang melakukan lelang di Tempat Pelelangan Ikan (TPI) Karangsong.

: id_ pembeli

Tabel 3. Rancangan Tabel Pembeli

\begin{tabular}{|c|c|c|c|}
\hline No. & Nama & Tipe Data & Keterangan \\
\hline 1 & id_pembeli & $\operatorname{Int}(11)$ & Nomor Id pembeli \\
\hline 2 & nama_pem & $\operatorname{Varchar}(50)$ & Nama pengguna \\
\hline 3 & nik & Char(30) & Nomor identitas pembeli \\
\hline 4 & alamat & Varchar(50) & Alamat pembeli \\
\hline
\end{tabular}

\section{Rancangan Tabel Pelelangan}

\section{Nama tabel : Pelelangan}

Deskripsi : Untuk menyimpan data pelelangan ikan yang dilakukan oleh nelayan dan pembeli di Tempat Pelelangan Ikan (TPI) Karangsong.

Primary key : no_lelang

Tabel 4. Rancangan Tabel Pelelangan

\begin{tabular}{|c|l|l|l|}
\hline No. & \multicolumn{1}{|c|}{ Nama } & \multicolumn{1}{|c|}{ Tipe Data } & \multicolumn{1}{c|}{ Keterangan } \\
\hline 1 & no_lelang & $\operatorname{Int}(11)$ & Nomor lelang \\
\hline 2 & tgl & Date & Tanggal transaksi pelelangan ikan \\
\hline 3 & id_nelayan & $\operatorname{Int}(11)$ & Nomor Id nelayan \\
\hline 4 & id_pembeli & $\operatorname{Int}(11)$ & Nomor Id pembeli \\
\hline
\end{tabular}




\begin{tabular}{|c|l|l|l|}
\hline 5 & nama_ikn & Varchar(50) & Nama ikan \\
\hline 6 & hrg_lelang & $\operatorname{Int}(20)$ & Harga lelang ikan per Kg \\
\hline 7 & berat_ikan & $\operatorname{Int}(5)$ & Berat ikan dalam Kg \\
\hline 8 & total_harga & $\operatorname{Int}(20)$ & Total harga lelang \\
\hline
\end{tabular}

\section{Rancangan Tabel Pendapatan}

Nama tabel : Pendapatan

Deskripsi : Untuk menyimpan data pendapatan nelayan dari hasil lelang di Tempat Pelelangan

Ikan (TPI) Karangsong.

Primary key : no_nota

Tabel 5. Rancangan Tabel Pendapatan

\begin{tabular}{|c|l|l|l|}
\hline No. & \multicolumn{1}{|c|}{ Nama } & \multicolumn{1}{|c|}{ Tipe Data } & \multicolumn{1}{c|}{ Keterangan } \\
\hline 1 & no_nota & $\operatorname{Int}(11)$ & Nomor nota \\
\hline 2 & no_lelang & $\operatorname{Int}(11)$ & Nomor lelang \\
\hline 3 & Id_nelayan & $\operatorname{Int}(11)$ & Nomor Id nelayan \\
\hline 4 & Hasil_lelang & $\operatorname{Int}(11)$ & Hasil dari pelelangan ikan \\
\hline 5 & jlm_biaya & $\operatorname{Int}(20)$ & Jumlah biaya jasa pelelangan \\
\hline
\end{tabular}

\section{Rancangan Relasi Tabel}

Setiap tabel harus mempunyai hubungan dengan yang lain, bila tidak ada penghubung antar tabel maka dapat dipastikan bahwa database kurang baik untuk digunakan. Hal ini dilakukan untuk memastikan kebenaran isi tabel dengan hubungannya antar tabel yang telah dibuat:

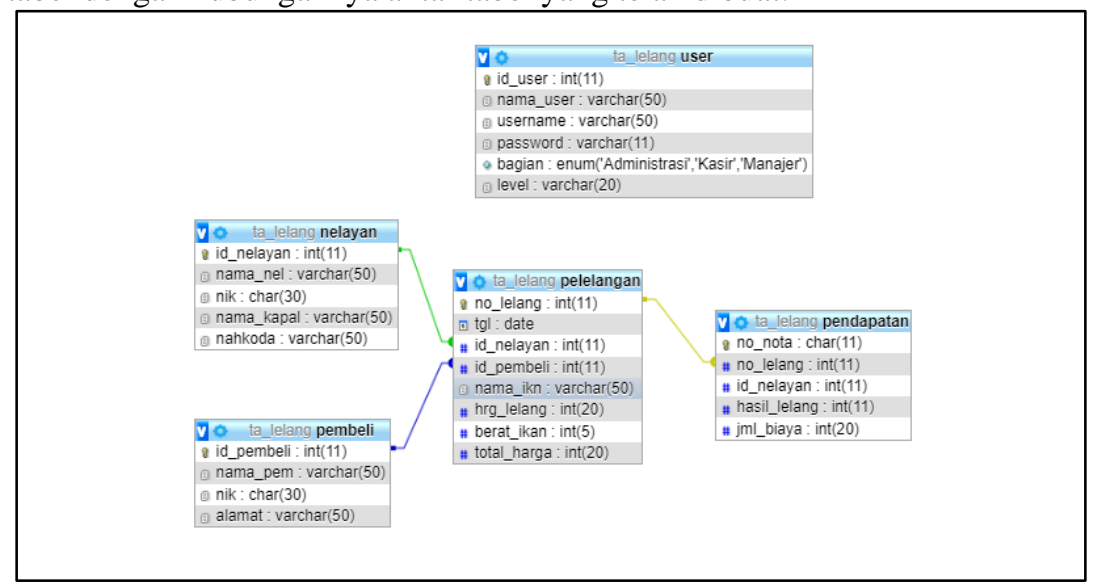

Gambar 3. Rancangan Relasi Tabel

\section{Rancangan Struktur Program}

Perancangan struktur program ini terdiri dari rancangan menu utama dan sub-sub menunya untuk membuat suatu program komputer yang sesuai dengan kebutuhan. Berikut merupakan rancangan struktur program pada sistem informasi akuntansi penerimaan kas atas transaksi pelelangan ikan pada Tempat Pelelangan Ikan (TPI) Karangsong Indramayu:

Sistem Informasi Akuntansi Penerimaan Kas Atas Transaksi Pelelangan Ikan Pada Tempat Pelelangan Ikan (TPI) Kecamatan Karangsong Kabupaten Indramayu - 


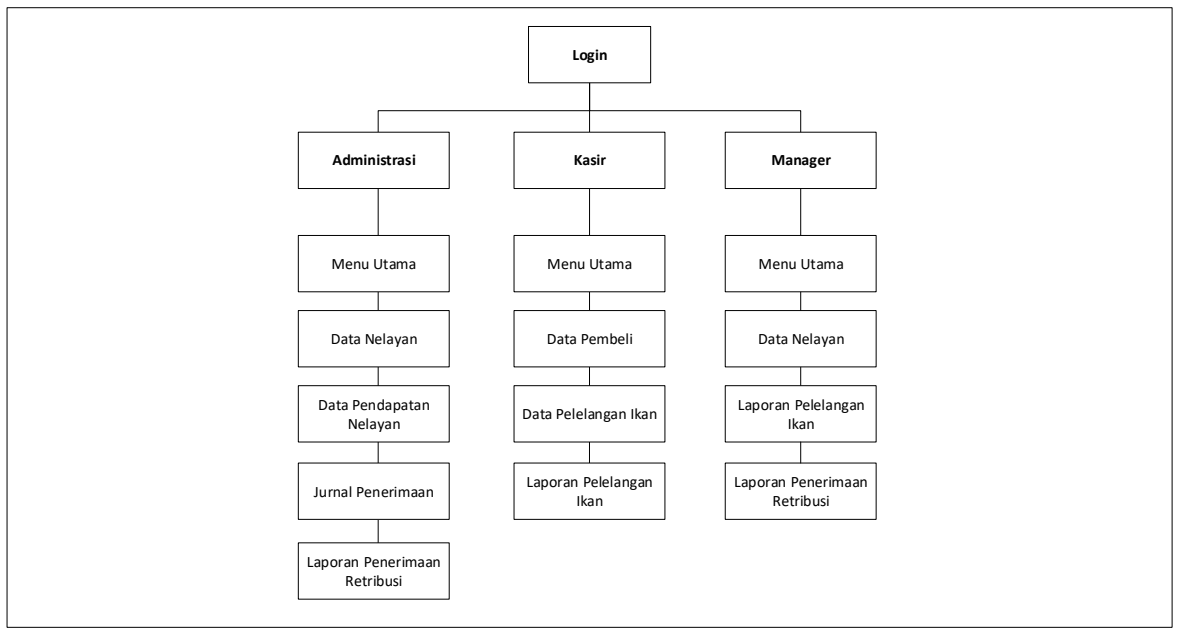

Gambar 4. Rancangan Struktur Program

Langkah-langkah untuk mengoperasikan susunan program diatas adalah sebagai berikut:

1. Langkah pertama adalah melakukan proses login dengan memasukkan username dan password masing-masing sesuai dengan bagian terkait yang bertujuan tidak semua orang dapat mengakses program ini. Dengan adanya form login ini kita dapat mengatur hak akses masing-masing pengguna, sehingga tidak terjadi kecurangan yang dapat merugikan perusahaan.

2. Setelah melakukan proses login sesuai dengan username dan password bagian yang terkait dalam sistem, maka akan tampil menu-menu yang telah ditentukan sesuai dengan bagiannya, berikut merupakan menu-menu yang terdapat pada tiap bagian:

1) Logout yaitu menu yang digunakan untuk keluar dari program, apabila pengguna telah melakukan proses logout maka pengguna akan dihadapkan dengan form untuk proses login kembali. Menu logout ini ada pada menu di setiap bagian.

2) Menu pada bagian administrasi terdiri dari:

a. Data Nelayan yaitu menu yang digunakan untuk melakukan input data nelayan dan menyimpan data nelayan.

b. Data Pendapatan Nelayan yaitu menu yang digunakan untuk melakukan input data hasil lelang ikan milik nelayan yang disimpan sebagai data pendapatan nelayan.

c. Jurnal Penerimaan yaitu menu yang digunakan untuk mencatat dan menampilkan semua penerimaan kas atas transaksi pelelangan ikan nelayan ke dalam bentuk jurnal.

d. Laporan Penerimaan Retribusi yaitu menu yang digunakan untuk mencatat semua penerimaan kas atas transaksi pelelangan ikan nelayan ke dalam bentuk laporan.

3) Menu pada bagian Kasir terdiri dari:

a. Data Pembeli yaitu menu yang digunakan untuk melakukan input data pembeli dan menyimpan data pembeli.

b. Data Pelelangan Ikan yaitu menu yang digunakan untuk melakukan input data pelelangan ikan dan menyimpan data pelelangan ikan.

c. Laporan Pelelangan Ikan yaitu menu yang digunakan untuk mencatat semua transaksi pelelangan ikan yang dilakukan nelayan dan pembeli ke dalam bentuk laporan dan menyimpan data tersebut.

4) Menu pada bagian Manajer terdiri dari:

a. Data Nelayan yaitu menu yang digunakan untuk menampilkan data nelayan yang telah di simpan oleh bagian administrasi.

b. Laporan Pelelangan Ikan yaitu menu yang digunakan untuk menampilkan data pelelangan ikan yang dilakukan nelayan dan pembeli dalam bentuk laporan dan menyimpan data tersebut.

Laporan Penerimaan Retribusi yaitu menu yang digunakan untuk menampilkan data penerimaan kas atas transaksi pelelangan ikan nelayan dalam bentuk laporan. 


\section{IMPLEMENTASI SISTEM}

Implementasi merupakan suatu tahapan hasil dari analisa dan penghasilan dan pengkajian dari datadata yang telah diproses sebelumnya tahap ini merupakan tahap akhir dari serangkaian sistem, dimana di dalamnya dilakukan penerapan aplikasi dari sistem yang telah dirangkai dan dirancang menjadi sebuah sistem baru sebagai sebuah keputusan akhir dari pengembangan sistem.

\subsection{Tampilan Input}

Tampilan input dan output merupakan halaman-halaman yang digunakan dalam sistem informasi akuntansi penerimaan kas atas transaksi pelelangan ikan pada Tempat Pelelangan Ikan (TPI) Karangsong Indramayu, halaman yang digunakan yaitu sebagai berikut :

\subsubsection{Form Login}

Form login adalah form yang digunakan oleh pengguna untuk masuk ke dalam menu utama berdasarkan hak akses yang dimilikinya. Dimana setisp pengguna memiliki hak akses yang berbeda-beda sesuai dengan bagiannya.

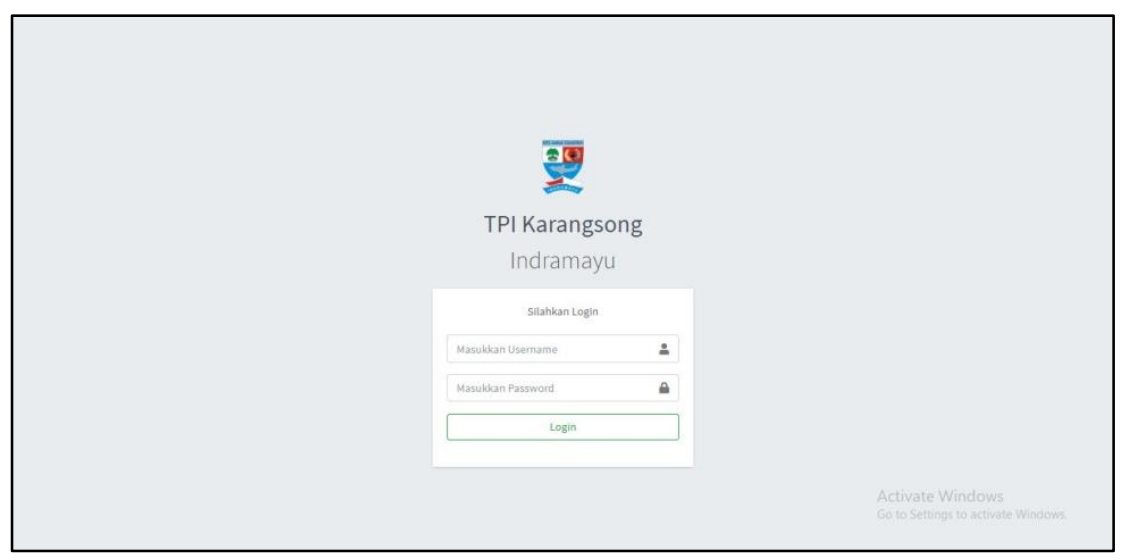

Gambar 5. Form Login

\subsection{Form Administrasi}

a. Form Menu Utama

Form menu utama pada bagian adminitrasi ini digunakan untuk melihat menu-menu apa saja yang dapat diakses oleh bagian administrasi.

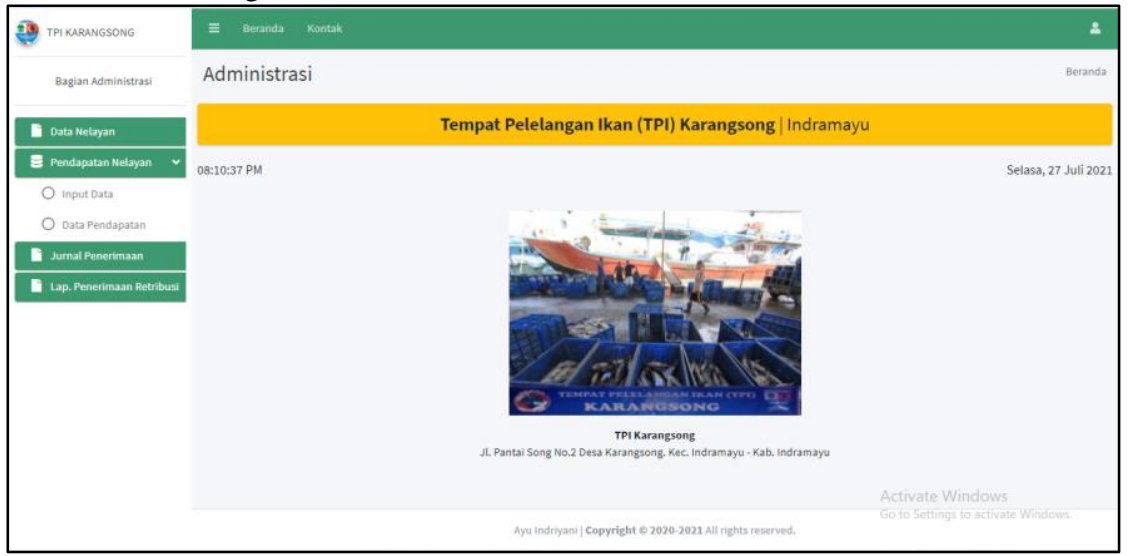

Gambar 6. Form Menu Utama

Sistem Informasi Akuntansi Penerimaan Kas Atas Transaksi Pelelangan Ikan Pada Tempat Pelelangan Ikan (TPI) Kecamatan Karangsong Kabupaten Indramayu -

(Ayu Indriani,Turini,Chairun Nas) 
b. Form Input Data Nelayan

Form input data nelayan pada bagian adminitrasi ini digunakan untuk menambah data nelayan baru secara lengkap yang dapat diakses oleh bagian administrasi.

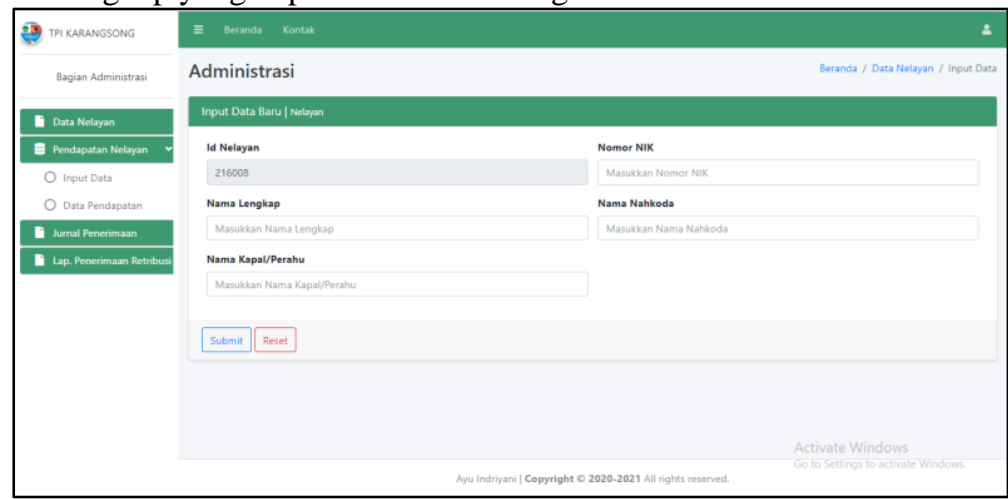

Gambar 7. Form Input Data Nelayan

c. Form Input Data Pendapatan Nelayan

Form input data pendapatan nelayan pada bagian adminitrasi ini digunakan untuk menambah data pendapatan nelayan baru atas pelelangan ikan secara lengkap yang dapat diakses oleh bagian administrasi.

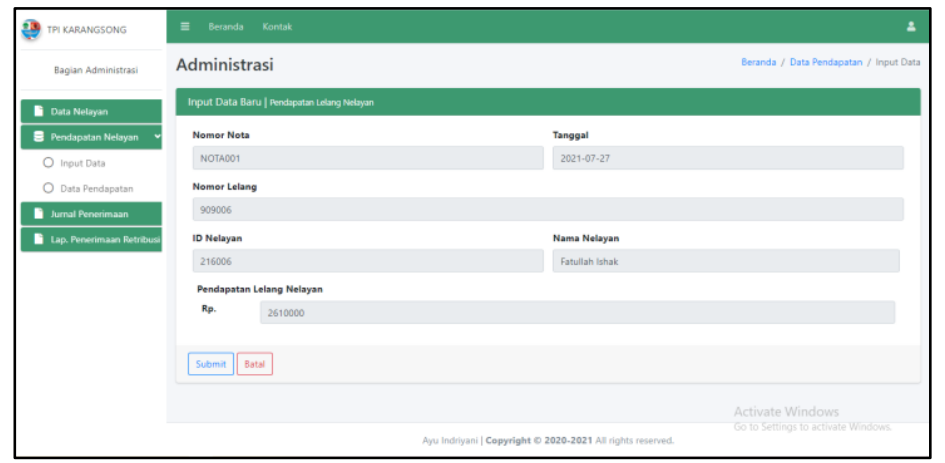

Gambar 8. Form Input Data Pendapatan Nelayan

d. Form Hasil Input Data Pendapatan Nelayan

Form hasil input data hasil lelang ikan nelayan ini digunakan untuk melihat data pendapatan nelayan yang sudah diinput secara lengkap yang dapat diakses oleh bagian administrasi.

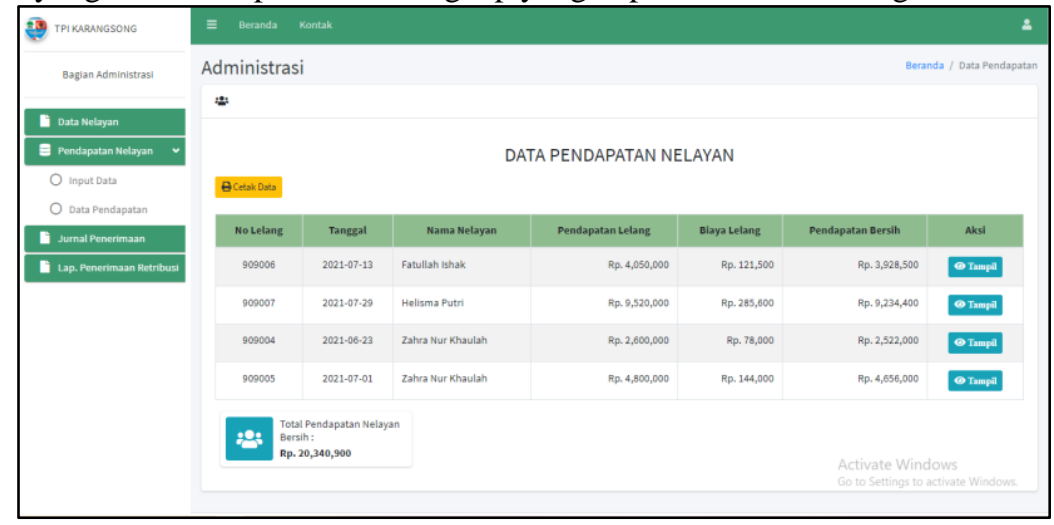

Gambar 9. Form Hasil Input Data Pendapatan Nelayan

e. Form Jurnal Penerimaan

Form jurnal penerimaan ini digunakan untuk mencatat dan menampilkan semua penerimaan kas atas transaksi pelelangan ikan nelayan yang dapat diakses oleh bagian administrasi. 


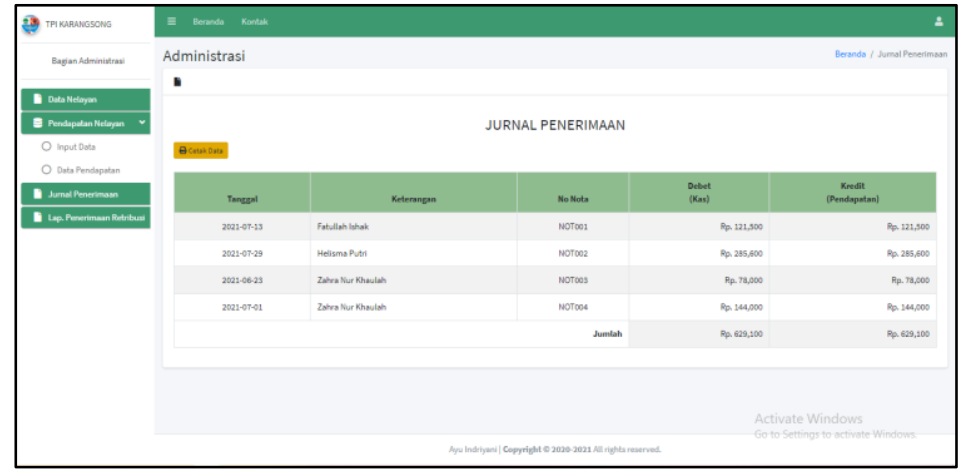

\section{Gambar 10. Form Jurnal Penerimaan}

f. Form Laporan Penerimaan Retribusi

Form Laporan Penerimaan Retribusi ini digunakan untuk menampilkan semua data penerimaan kas atas transaksi pelelangan ikan nelayan yang dapat diakses oleh bagian administrasi.

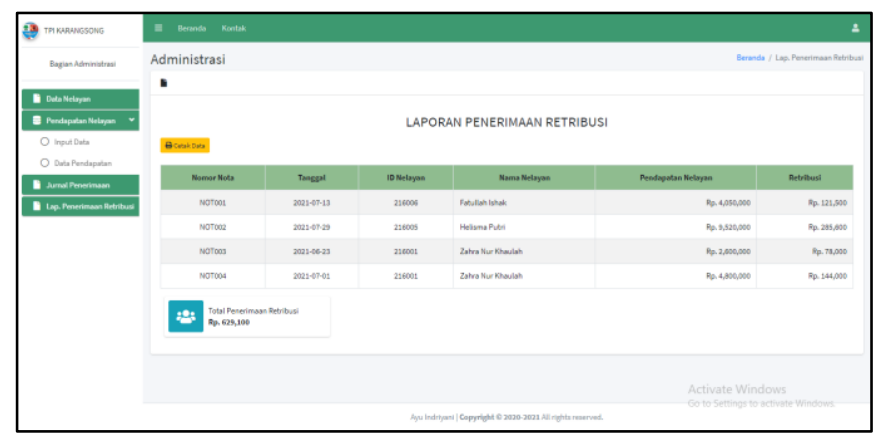

Gambar 11. Form Laporan Penerimaan Retribusi

\section{Form Kasir}

a. Form Menu Utama

Form menu utama pada bagian kasir ini digunakan untuk melihat menu-menu apa saja yang dapat diakses oleh bagian kasir.

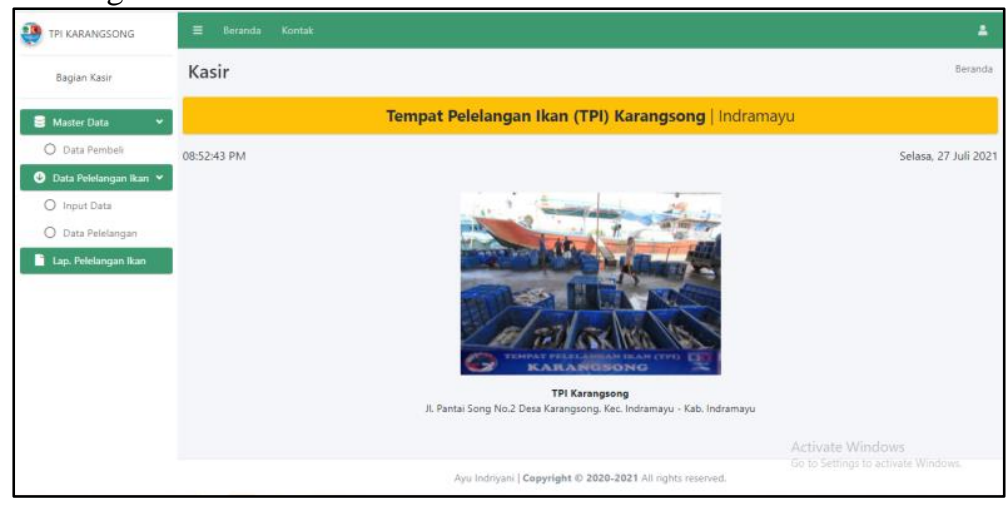

Gambar 12. Form Menu Utama Kasir

Sistem Informasi Akuntansi Penerimaan Kas Atas Transaksi Pelelangan Ikan Pada Tempat Pelelangan Ikan (TPI) Kecamatan Karangsong Kabupaten Indramayu (Ayu Indriani,Turini,Chairun Nas) 
b. Form Input Data Pembeli

Form input data pembeli pada bagian adminitrasi ini digunakan untuk menambah data pembeli baru secara lengkap yang dapat diakses oleh bagian kasir.

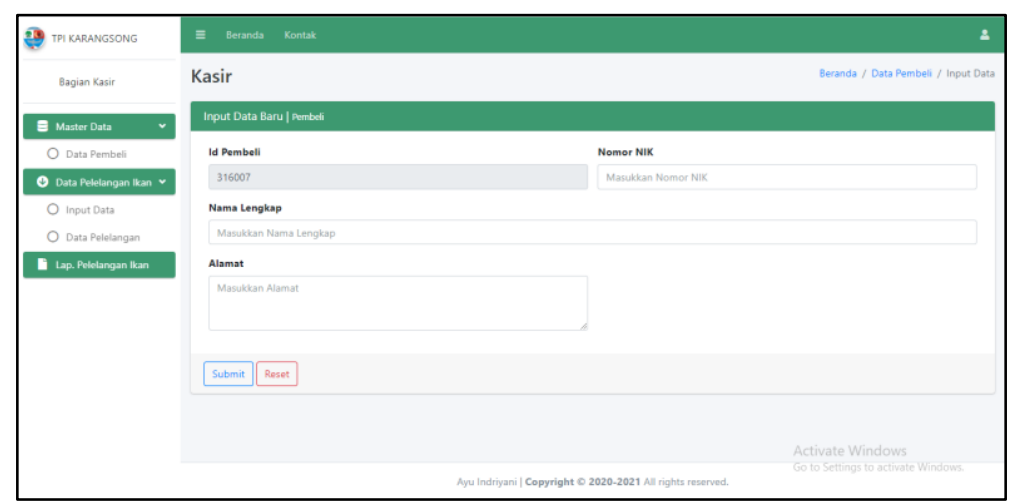

Gambar 13.Form Input Data Pembeli

c. Form Tampil Nota Lelang Pembeli

Form tampil Nota Lelang ini digunakan untuk melihat nota lelang pembeli yang sudah dilakukan input secara lengkap yang dapat diakses oleh bagian kasir.

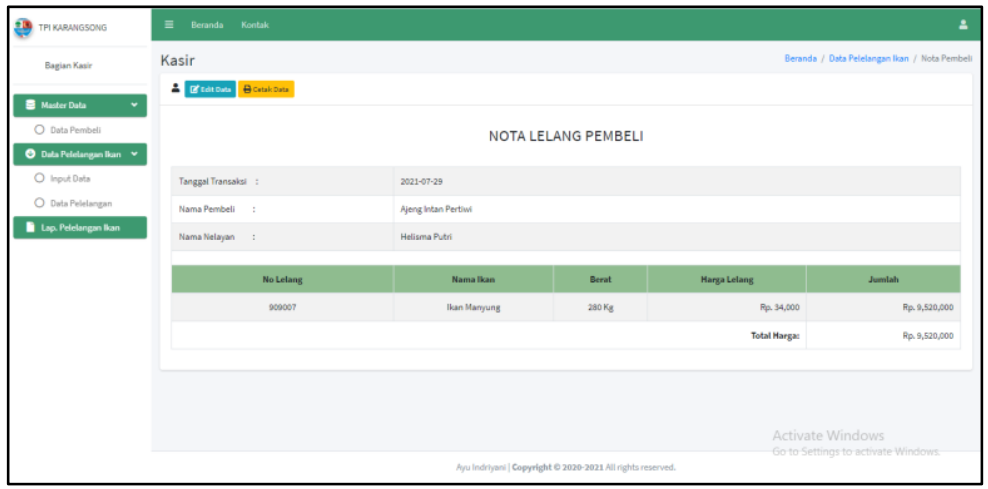

Gambar 14. Form Nota Lelang Pembeli

d. Form Laporan Pelelangan Ikan

Form laporan pelelangan ikan ini digunakan untuk menampilkan semua data pelelangan ikan yang telah di input secara lengkap dan dapat diakses oleh bagian kasir.

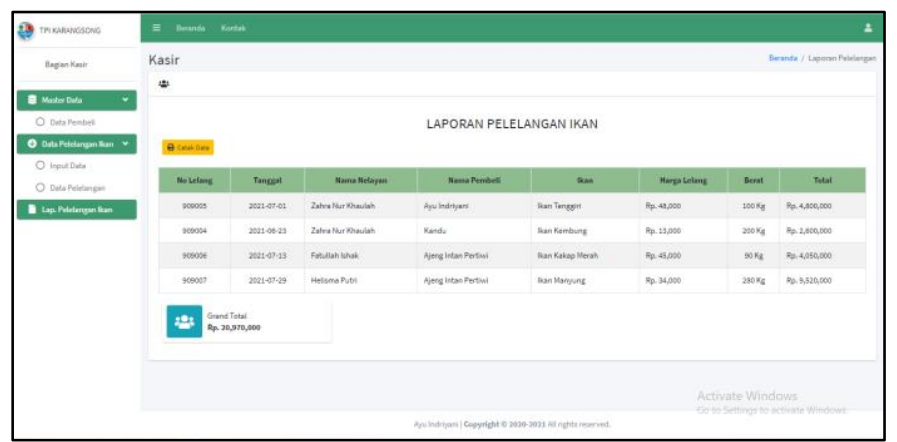

Gambar 15. Form Laporan Pelelangan Ikan 


\section{Form Manajer}

a. Form Menu Utama

Form menu utama pada bagian manajer ini digunakan untuk melihat menu-menu apa saja yang dapat diakses oleh bagian manajer.

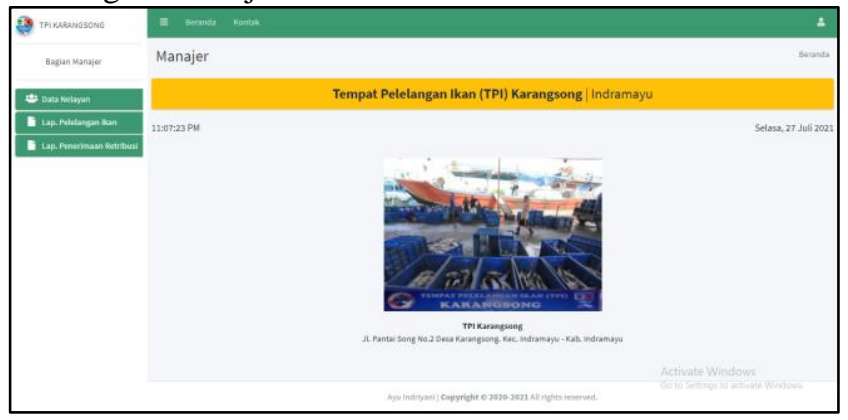

Gambar 16. Form Menu Utama Manajer

b. Form Laporan Data Nelayan

Form laporan data nelayan pada bagian manajer ini digunakan untuk melihat data nelayan yang sudah diinput secara lengkap oleh bagian administrasi yang dapat diakses oleh bagian manajer.

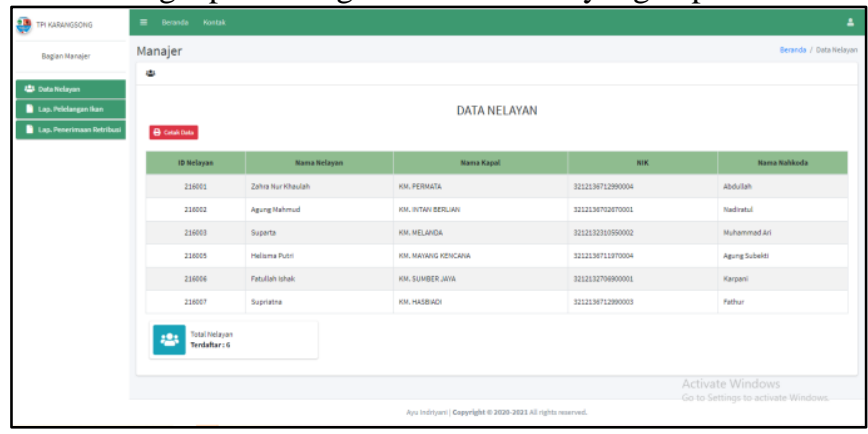

Gambar 17. Form Laporan Data Nelayan

c. Form Laporan Pelelangan Ikan

Form laporan pelelangan ikan pada bagian manajer ini digunakan untuk menampilkan semua data pelelangan ikan yang sudah diinput secara lengkap oleh bagian kasir yang dapat diakses oleh bagian manajer.

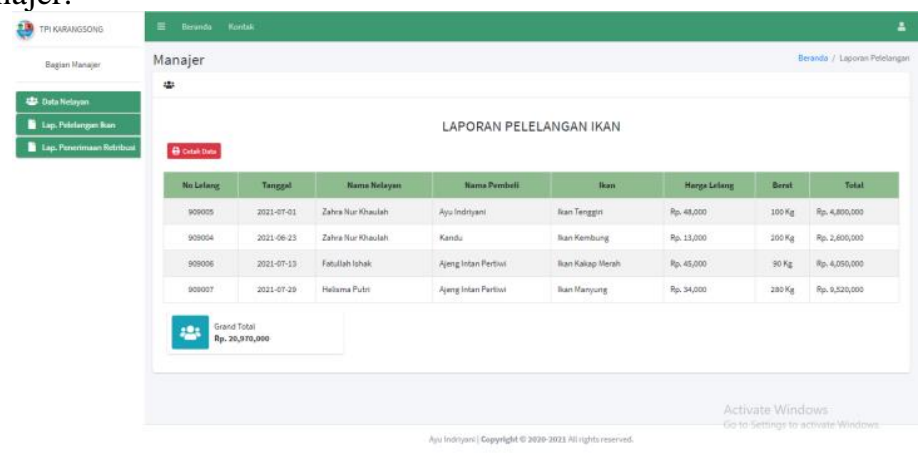

Gambar 18. Form Laporan Pelelangan Ikan

Sistem Informasi Akuntansi Penerimaan Kas Atas Transaksi Pelelangan Ikan Pada Tempat Pelelangan Ikan (TPI) Kecamatan Karangsong Kabupaten Indramayu (Ayu Indriani,Turini, Chairun Nas) 
d. Form Laporan Penerimaan Retribusi

Form laporan penerimaan retribusi pada bagian manajer ini digunakan untuk melihat semua data penerimaan yang sudah diinput secara lengkap oleh bagian administrasi yang dapat diakses oleh bagian manajer.

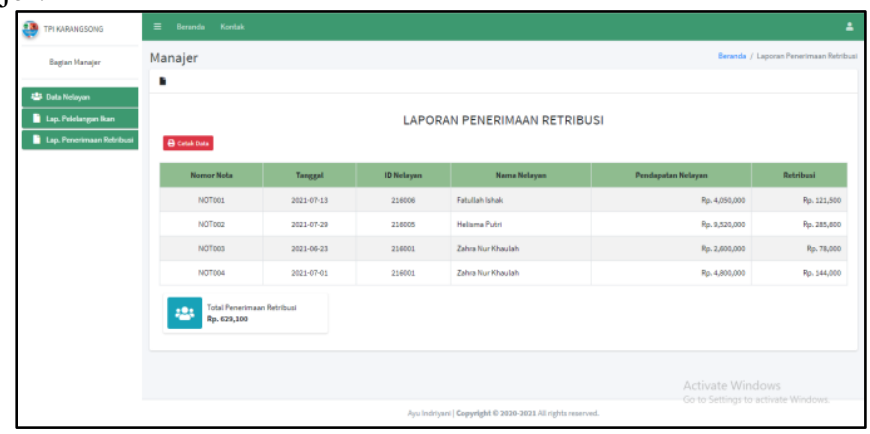

Gambar 19. Form Laporan Penerimaan Retribusi

\section{KESIMPULAN}

\subsection{Kesimpulan}

Berdasarakan hasil analisa yang telah dilakukan pada bab III tentang sistem informasi akuntansi penerimaan kas atas transaksi pelelangan ikan pada Tempat Pelelangan Ikan (TPI) Kecamatan Karangsong Kabupaten Indramayu, maka dari itu penulis menarik beberapa kesimpulan dari data yang telah dibuat sebagai berikut :

1. Sistem ini dirancang untuk membuat proses pencatatan penerimaan kas atas transaksi pelelangan ikan pada Tempat Pelelangan Ikan (TPI) Karangsong Indramayu menjadi lebih efektif.

2. Menerapkan pengendalian internal terhadap sistem pencatatan penerimaan kas atas transaksi pelelangan ikan pada Tempat Pelelangan Ikan (TPI) Karangsong Indramayu.

3. Membuat sistem aplikasi berbasis web untuk pencatatan penerimaan kas atas transaksi pelelangan ikan pada Tempat Pelelangan Ikan (TPI) Karangsong Indramayu.

\subsection{Saran}

Adapun saran yang penyusun berikan untuk pengembangan aplikasi ini selanjut nya antara lain :

1. Pengembangan kedepannya aplikasi ini diharapkan dapat membuat pegelolaan laporan keuangan berdasarkan periode tertentu pada data hasil pelelangan di Tempat Pelelangan Ikan (TPI) Karangsong.

2. Dalam pengembangannya program ini diharapkan dapat menampilkan grafik data pelelangan ikan dan penerimaan retribusi dalam setiap bulannya.

\section{DAFTAR PUSTAKA}

[1] Anton, Suyatno. 2016. Kepastian Hukum Dalam Penyelesaian Kredit Macet Melalui Eksekusi Jaminan Hak Tanggungan Tanpa Proses Gugatan Pengadilan. Jakarta: P.T. Fajar Interpratama Mandiri.

[2] Kartikahadi, Hans., dkk. 2016. Akuntansi Keuangan Menengah Berbasis SAK Berbasis IFRS. Buku 1. Jakarta : Salemba Empat.

[3] Mulyadi. 2016. Sistem Informasi Akuntansi. Jakarta: Salemba Empat.

[4] Mulyani, Sri . 2016. Metode Analisis dan Perancangan Sistem. Bandung: Abdi SisteMatika.

[5] Sudarwanto, Adenk. 2013. Akuntansi Koperasi. Edisi 1. Yogyakarta: Graha Ilmu.

[6] Sujarweni, V. Wiratna. 2015. Statistik untuk Bisnis dan Ekonomi. Yogyakarta: Pustaka Baru Press.

[7] Wijaya, D. Dimas Andi. 2014. Analisis dan Perancangan Sistem Akuntansi Penerimaan Kas. Yogyakarta. 